\begin{tabular}{|c|c|c|c|}
\hline $\mathrm{n} / \mathrm{N}(\%)$ & $\begin{array}{l}\text { TAF } \\
(\mathrm{N}=243)\end{array}$ & $\begin{array}{l}\text { TDF } \\
(\mathrm{N}=245)\end{array}$ & $P$ value \\
\hline \multicolumn{4}{|l|}{ Efficacy } \\
\hline$H B V$ DNA $\geq 20 \mathrm{IU} / \mathrm{mL}^{\mathrm{a}}$ & $1 / 243(0.4)$ & 1/245(0.4) & $0.95^{b}$ \\
\hline HBV DNA < $20 \mathrm{IU} / \mathrm{mL}$ & $234 / 243(96.3)$ & 236/245 (96.3) & 0.98 \\
\hline No virologic data in Week 48 window & $8 / 243(3.3)$ & $8 / 245(3.3)$ & - \\
\hline ALT normal (2018 AASLD criteria) $)^{c, d}$ & $192 / 243(79)$ & $184 / 245(75.1)$ & 0.31 \\
\hline HBsAg seroconversion ${ }^{e}$ & $2 / 78(2.6)$ & 0 & 0.13 \\
\hline HBsAg seroconversion & 0 & 0 & - \\
\hline \multicolumn{4}{|l|}{ Bone safety } \\
\hline Hip BMD, mean (SD)\% change & $+0.66(2.08)$ & $-0.51(1.91)$ & $<0.001$ \\
\hline Spine BMD, mean (SD)\% change & $+1.74(3.46)$ & $-0.11(3.13)$ & $<0.001$ \\
\hline $\begin{array}{l}\mathrm{CTX} \text {, median }(\mathrm{Q} 1, \mathrm{Q} 3) \% \text { change }(\mathrm{ng} / \\
\mathrm{mL})^{f}\end{array}$ & $\begin{array}{l}-29.4(-44.2,- \\
14.3)\end{array}$ & $+7.1(-14.8,32)$ & $<0.001$ \\
\hline $\begin{array}{l}\text { P1NP, median (Q1, Q3)\% change (ng/ } \\
\mathrm{mL})^{\mathrm{g}}\end{array}$ & $\begin{array}{l}-19.4(-32.2,- \\
7.5)\end{array}$ & $+1.70(-12.4,17)$ & $<0.001$ \\
\hline \multicolumn{4}{|l|}{ Renal safety } \\
\hline $\begin{array}{l}\text { eGFR }{ }_{\mathrm{CG}} \text { median }(\mathrm{Q} 1, \mathrm{Q} 3) \text { change }(\mathrm{mL} / \\
\mathrm{min})\end{array}$ & $\begin{array}{l}+0.99(-4.47, \\
6.31)\end{array}$ & $\begin{array}{l}-2.74(-7.87 \\
1.98)\end{array}$ & $<0.001$ \\
\hline $\mathrm{RBP} / \mathrm{Cr}$, median (Q1, Q3)\% change $^{\mathrm{h}}$ & $\begin{array}{l}-17.7(-41.3, \\
17.2)\end{array}$ & $\begin{array}{l}+18.6(-15.3, \\
67.3)\end{array}$ & $<0.001$ \\
\hline$\beta 2 \mathrm{MG} / \mathrm{Cr}$, median $(\mathrm{Q} 1, \mathrm{Q} 3) \%$ change $^{\mathrm{i}}$ & $\begin{array}{l}-36.0(-61.9 \\
1.1)\end{array}$ & $\begin{array}{l}+10.7(-33.9, \\
90.6)\end{array}$ & $<0.001$ \\
\hline
\end{tabular}

aHBV DNA results by modified US FDA Snapshot algorithm; other efficacy data are missing=failure; 'bStratified Cochran-Mantel-Haenszel test; 'ALT normal is the proportion with ALT $\leq$ ULN at Week 48, regardless of baseline status; ${ }^{d}$ ULN 35 U/L males, 25 U/L females; ${ }^{\mathrm{e}} \mathrm{HBeAg-positive} \mathrm{at} \mathrm{baseline;}{ }^{\mathrm{f}} \mathrm{C}$-type collagen sequence (bone resorption marker); ${ }^{9}$ Procollagen type $1 \mathrm{~N}$-terminal propeptide (bone formation marker); ${ }^{\mathrm{h}}$ Retinol binding protein/creatinine (tubular marker); 'Beta-2 microglobulin/creatinine (tubular marker).

prespecified secondary safety endpoints were changes in hip and spine bone mineral density (BMD), estimated creatinine clearance by Cockcroft-Gault $\left(\mathrm{eGFR}_{\mathrm{CG}}\right)$, and markers of bone turnover and renal tubular function. Viral resistance was evaluated by population sequencing those patients who experienced virologic breakthrough or viremia at the time of discontinuation.

Results 488 patients were randomized and treated. At baseline the groups were similar: median age $52 \mathrm{y}, 71 \%$ male, $82 \%$ Asian, 68\% HBeAg-negative, median ALT $23 \mathrm{U} / \mathrm{L}$, median eGFR $_{\mathrm{CG}} 90.5 \mathrm{~mL} / \mathrm{min} ; 45 \%$ and $50 \%$ had low BMD by $\mathrm{T}$ scores at hip and spine, respectively. Median (Q1, Q3) duration of prior TDF was $222(145,305)$ weeks. Key efficacy/safety results are summarized (table 1). TAF demonstrated non-inferior efficacy to TDF with a similar rate $(0.4 \%)$ of having HBV DNA ${ }^{3} 20 \mathrm{IU} / \mathrm{mL}$ at Week 48 . TAF resulted in hip/spine BMD increases with less impact on bone turnover makers; switching from TDF to TAF resulted in $\mathrm{eGFR}_{\mathrm{CG}}$ increases and decreased tubular function markers. Rates of ${ }^{3}$ Grade 2 adverse events (AEs) and serious AEs were low and similar between groups. No viral resistance was observed.

Conclusions Virologically-suppressed CHB patients who were switched to TAF demonstrated noninferior efficacy to continued TDF with improved bone and renal safety.

\section{IDDF2019-ABS-0170 ENDOSCOPIC HUMAN THROMBIN INJECTION-PROMISING AND SAFE THERAPY FOR THE MANAGEMENT OF BLEEDING GASTRIC VARICES}

Ashok Jhajharia*, Mayank Ameta, Deepak Sharma, Prachis Ashdhir, Rupesh Pokharna. SMS Medical College and Hospital, India

\subsection{6/gutjnl-2019-IDDFabstracts.279}

Background Human thrombin appears to be a new effective tool in the armamentarium of management of bleeding gastric varices, but here are paucity of data on its use. Thus, we share our experience with human thrombin in the treatment of bleeding gastric varices.

Methods It was a prospective interventional study conducted between September 2015 and Feb 2019. Patients with upper gastrointestinal bleeding from gastric varices were included, while patients with the previous history of cyanoacrylate glue injection or band ligation were excluded. One vial of human thrombin contains $500 \mathrm{IU}$ which was reconstituted with $1 \mathrm{ml}$ of calcium chloride and $4 \mathrm{ml}$ distilled water. Each $\mathrm{ml}$ of reconstituted solution contains 100 IU which was injected into bleeding varices with standard sclerotherapy needle. Amount of thrombin injected depends on the size of varix. (figure 1) Results A total of 30 patients (M:F-23:7) with mean age 33.1 [17-60] years) presenting with gastric variceal bleeding requiring endoscopic injection of human thrombin were studied. The underlying diagnosis was cirrhosis in 12 patients(40\%), extrahepatic portal vein thrombosis in 9 patients(30\%), noncirrhotic portal fibrosis in 4 patients(13.3\%), chronic pancreatitis in 3 patients (10\%),Budd Chiari syndrome in 2 patients $(6.6 \%)$.

Isolated gastric varices were found in 9 patients while 20 patients had gastroesophageal varices (GOV) (GOV1-3, GOV2-17), ectopic jejunal varices were seen in 1 patient. Patients received 1 to 3 sessions (mean $=1.3$ ) of thrombin with a mean total dose of 600 IU (range $=500-1500$ IU). Mean follow up was 33 months (range 3-42 months). Hemostasis in the acute setting was successfully managed in all the

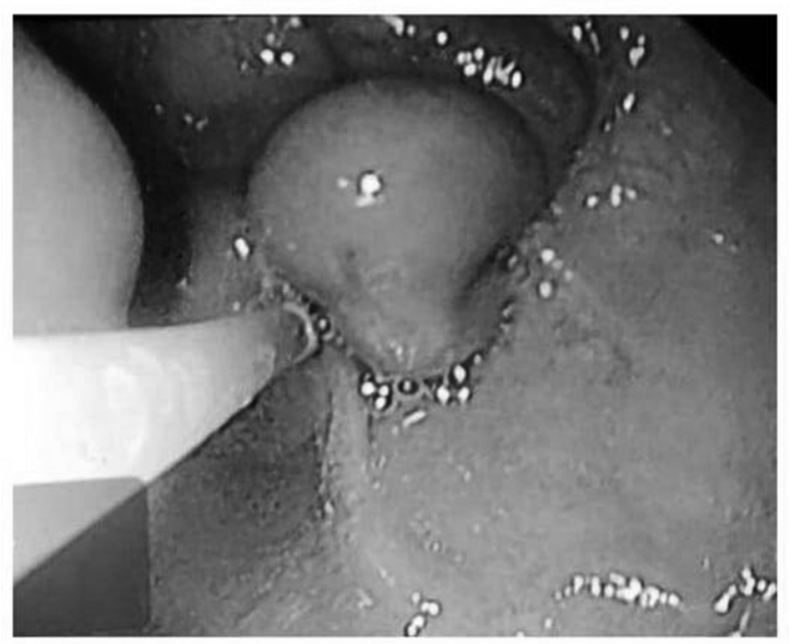

FIGURE- ECTOPIC VARICES IN JEJUNUM

Abstract IDDF2019-ABS-0170 Figure 1 


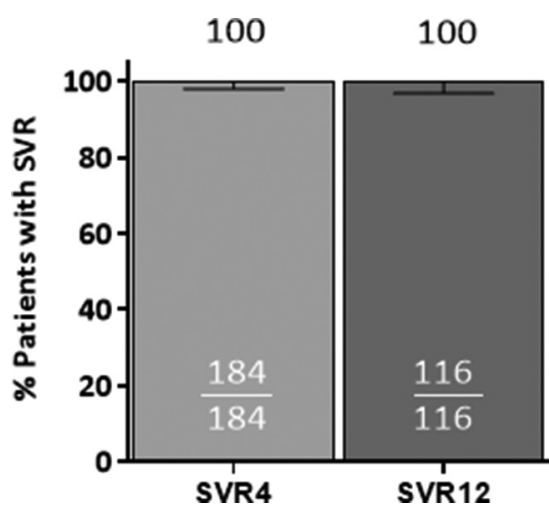

Abstract IDDF2019-ABS-0210 Figure 1 Efficacy to date

30 patients on initial presentation. On serial follow up, 9 out of 20 patients required repeat endoscopic session for gastric varices. No thrombin injection-related complication was recorded.

Conclusions Endoscopic therapy with thrombin appears safe and effective in the management of bleeding gastric varices.

\section{IDDF2019-ABS-0194 THE ROLE OF TOCOTRIENOLS IN THE TREATMENT OF NON-ALCOHOLIC STEATOHEPATITIS- A META-ANALYSIS}

Richton Eder* , Higinio Mappala. Jose R. Reyes Mem. Medical Center, Philippines

\subsection{6/gutjnl-2019-IDDFabstracts.280}

Background Chronic liver diseases (CLD) represent a major public health problem, accounting for significant mortality of more than 1.75 million deaths are attributed to it. Among these, Non-alcoholic fatty liver disease (NAFLD) is a rapidly increasing cause, with an estimated $13.5 \%$ to $31.8 \%$ affected globally. Asia has a $33 \%$ prevalence rate based on a population study. NAFLD includes a wide spectrum of conditions, from a simple fatty liver, nonalcoholic steatohepatitis (NASH) and cirrhosis or liver cancer. Recent studies have shown that the risk of developing NASH is 4-11 times higher in patients with metabolic syndrome as compared with healthy individuals. The mainstay of treatment for NAFLD is the adoption of healthy lifestyle modification. However, among all the therapeutic options based on recent guidelines, Vitamin E appears to be the frontline treatment for non-alcoholic steatohepatitis (NASH) in non-diabetic adults, with potent anti-inflammatory and antioxidant properties which may reduce liver injury in NAFLD. Tocotrienols have been revered as the new Vitamin E, which is 100 times more absorbed than Tocopherol and with more efficient penetration into the fat tissues. The study focuses on the hepatoprotective effects of Tocotrienol in patients with NASH.

Methods The RCTs reviewed involved 128 non-diabetic patients with 61 patients receiving Tocotrienol (experimental group) at $200 \mathrm{mg} / \mathrm{tab}$, twice daily and 67 patients given placebo (control group). The subject population is demographically homogenous. Other causes of CLD were excluded. Outcome measure includes the reduction in liver transaminases. Statistical tools include the use of Review Manager (RevMan). Sensitivity analysis was analyzed using MantelHaenszel procedure for binary data to determine the clinical significance of the effect. Sensitivity analysis was two-tailed, set at $\mathrm{p}$-value $<0.05$. Heterogeneity was calculated with $\mathrm{i}^{2}$ statistics. Odds ratio was assessed at 95\% confidence interval (CI).

Results Results in this meta-analysis

Non-diabetic patients receiving tocotrienols had significant reduction of liver transaminases specifically ALT with a p-value of $<0.002$.

The table is attached (figure 1).

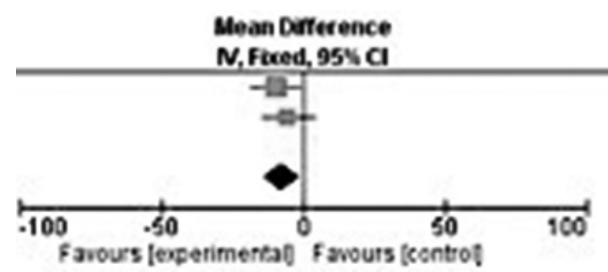

Abstract IDDF2019-ABS-0194 Figure 1

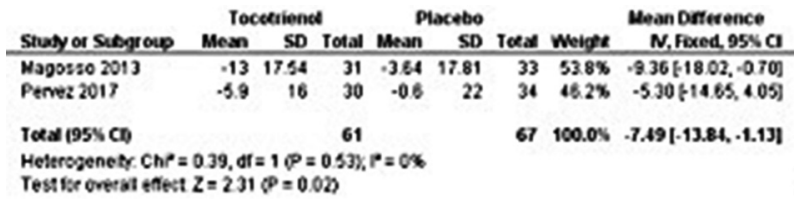

\section{Abstract IDDF2019-ABS-0194 Table 1}

Conclusions This study showed that tocotrienols may have significant hepatoprotective effects in NASH patients in terms of reduction of ALT levels.

\section{IDDF2019-ABS-0199 THE RISK OF METABOLIC ACIDOSIS IN DIABETIC PATIENTS WITH DIFFERENT SEVERITY OF CHRONIC HEPATITIS B- RELATED CIRRHOSIS AND RENAL IMPAIRMENT}

Terry Cheuk-Fung Yip*, Vincent Wai-Sun Wong, Henry Lik-Yuen Chan, Yee-Kit Tse, Grace Lai-Hung Wong. Institute of Digestive Disease, Department of Medicine and Therapeutics, The Chinese University of Hong Kong; Hong Kong SAR, China

\subsection{6/gutjnl-2019-IDDFabstracts.281}

Background We examined the interaction between severity of renal and liver impairment on the risk of metabolic acidosis in diabetic patients with chronic hepatitis B (CHB)-related cirrhosis.

Methods This is a retrospective cohort study on diabetic patients with CHB-related cirrhosis between January 2000 and December 2017 using Clinical Data Analysis and Reporting System, which is a territory-wide electronic healthcare database that captures in-patient and out-patient data of all public hospitals and clinics and represents $90 \%$ of the 7.3 million Hong Kong population. Metabolic acidosis was defined by blood $\mathrm{pH} \leq 7.35$ with arterial bicarbonate $\leq 18 \mathrm{mmol} / \mathrm{L}$ or venous bicarbonate $\leq 21 \mathrm{mmol} / \mathrm{L}$ or lactate $>5 \mathrm{mmol} / \mathrm{L}$, and/or diagnosis codes. Renal and liver function were modelled by timedependent estimated glomerular filtration rate (eGFR) category and Child-Pugh class. Time-dependent medication uses and comorbidities were included in Fine-Gray model adjusted for competing for death. We excluded patients with eGFR $<30$ $\mathrm{mL} / \mathrm{min} / 1.73 \mathrm{~m}^{2}$ or renal replacement therapy at baseline.

Results Of 4,431 diabetic patients with CHB-related cirrhosis, $3,216(72.6 \%)$ were male; the mean age (SD) was $60.8(10.8)$ 